\title{
A low-temperature, photoinduced thiol-ene click reaction: a mild and efficient method for the synthesis of sugar-modified nucleosides $\uparrow$
}

\author{
Miklós Bege, Ilona Bereczki, Mihály Herczeg, Máté Kicsák, Dániel Eszenyi, \\ Pál Herczegh and Anikó Borbás (D)
}

Sugar-modified nucleosides are prime synthetic targets in anticancer and antiviral drug development. Radical mediated thiol-ene coupling was applied for the first time on nucleoside enofuranoside derivatives to produce a broad range of thio-substituted D-ribo, -arabino, -xylo and L-lyxo configured pyrimidine nucleosides. In contrast to the analogous reactions of simple sugar exomethylenes, surprisingly, hydrothiolation of nucleoside alkenes under the standard conditions of various initiation methods showed low to moderate yields and very low stereoselectivity. Optimizing the reaction conditions, we have found that cooling the reaction mixture has a significant beneficial effect on both the conversion and the stereoselectivity, and UV-light initiated hydrothiolation of C2'-, C3'- and C4'-exomethylene derivatives of nucleosides at $-80{ }^{\circ} \mathrm{C}$ proceeded in good to high yields, and, in most cases, in excellent diastereoselectivity. Beyond the temperature, the solvent, the protecting groups on nucleosides and, in some cases, the configuration of the thiols also affected the stereochemical outcome of the additions. The anomalous L-lyxo diastereoselectivity observed upon the addition of 1-thio- $\beta$-D-gluco- and galactopyranose derivatives onto $C 4^{\prime}, 5^{\prime}$-unsaturated uridines is attributed to steric mismatch between the $\mathrm{D}$-ribo $C 4^{\prime}$ radical intermediates and the $\beta$-configured 1-thiosugars.

Received 31st August 2017, Accepted 23rd October 2017

DOI: $10.1039 / c 70 b 02184 d$

rsc.li/obc
The radical-mediated addition of thiols to non-activated alkenes, ${ }^{5}$ also known as thiol-ene coupling, had widespread application in materials chemistry and chemical biology during the last few years. ${ }^{6}$ Due to mild conditions, atom economy and regioselectivity, this process has been extensively utilised in glycochemistry. ${ }^{7}$ We and others have reported that sugar-derived alkenes, including endo- and exoglycals, can be employed as acceptor substrates in the photoinitiated thiolene chemistry to produce various thiosugars and $S$-linked glycoconjugates in excellent stereoselectivity. ${ }^{8-10}$ Although only two examples have emerged in the literature with furanoid alkenes, both demonstrated that hydrothiolation of 3-exomethylene- ${ }^{8 c}$ and 4-exomethylene-furanosides ${ }^{9 a}$ showed complete stereoselectivity.

On the basis of the above results, we envisioned the extension of the photoinitiated thiol-ene reaction to nucleoside enofuranoside derivatives.

\section{Results and discussion}

We first investigated the addition of 1-propanethiol to the easily available $4^{\prime}, 5^{\prime}$-unsaturated uridine $\mathbf{1}$, under previously established standard conditions for the synthesis of $S$-glycoconjugates, ${ }^{8}$ irradiating at $\lambda_{\max }=365 \mathrm{~nm}$ at room temp- 


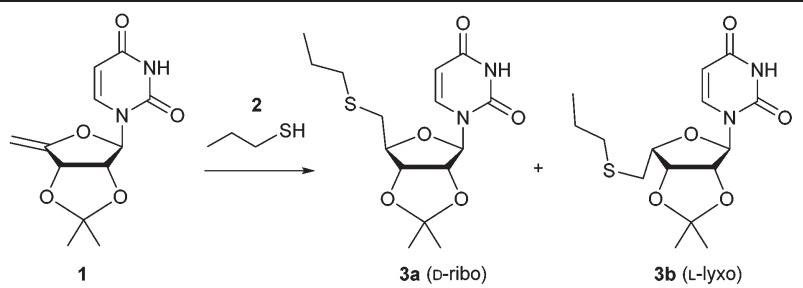

\begin{tabular}{|c|c|c|c|c|c|c|c|}
\hline Entry & Thiol equiv. & Initiation & Solvent & $T$ & Time & D-Ribo: L-lyxo ${ }^{b}$ & Yield $^{c}(\%)$ \\
\hline 1 & 3 & DPAP, $h \nu^{d}$ & Toluene & $\mathrm{rt}$ & $3 \times 15 \min$ & $2: 1$ & 60 \\
\hline 2 & 6 & DPAP, $h \nu^{d}$ & Toluene & $\mathrm{rt}$ & $3 \times 15 \mathrm{~min}$ & $2: 1$ & 69 \\
\hline 3 & 8 & AIBN & Toluene & $120^{\circ} \mathrm{C}$ & $6 \mathrm{~h}$ & $1.5: 1$ & 54 \\
\hline 4 & 3 & $\mathrm{Et}_{3} \mathrm{~B}$ & $\mathrm{CH}_{2} \mathrm{Cl}_{2}$ & rt & 2 days & $2: 1$ & 38 \\
\hline 5 & 3 & $\mathrm{Et}_{3} \mathrm{~B}$, catechol & $\mathrm{CH}_{2} \mathrm{Cl}_{2}$ & $\mathrm{rt}$ & $4 \mathrm{~h}$ & $2: 1$ & 59 \\
\hline 6 & 4 & $\mathrm{TiO}_{2}, h \nu^{e}$ & $\mathrm{CH}_{2} \mathrm{Cl}_{2}$ & $\mathrm{rt}$ & 2 days & $2: 1$ & 7 \\
\hline 7 & 2 & DPAP, $h \nu^{d}$ & Toluene & $-30^{\circ} \mathrm{C}$ & $3 \times 15 \mathrm{~min}$ & $4: 1$ & 88 \\
\hline 8 & 2 & DPAP,$h \nu^{d}$ & Toluene & $-80^{\circ} \mathrm{C}$ & $3 \times 15 \mathrm{~min}$ & $5: 1$ & 89 \\
\hline 9 & 2 & DPAP, $h \nu^{d}$ & Toluene-MeOH & $-80^{\circ} \mathrm{C}$ & $3 \times 15 \min$ & $6.3: 1$ & 88 \\
\hline $10^{f}$ & 2 & $\mathrm{Et}_{3} \mathrm{~B}$, catechol & $\mathrm{CH}_{2} \mathrm{Cl}_{2}-\mathrm{MeOH}$ & -80 to $-20{ }^{\circ} \mathrm{C}$ & $24 \mathrm{~h}$ & $2.5: 1$ & 64 \\
\hline
\end{tabular}

${ }^{a}$ The reactions were carried out on a $0.2-0.5 \mathrm{mmol} \mathrm{scale} .{ }^{b}$ Ratio of products determined by ${ }^{1} \mathrm{H}$ NMR. ${ }^{c}$ Overall yield of products isolated by column chromatography and the low yield was caused by low conversion of 1 . $^{d}$ Irradiation by UV light $\left(\lambda_{\max }=365 \mathrm{~nm}\right)$, the reaction was carried out in a borosilicate vessel without any caution to exclude air or moisture. ${ }^{e}$ Irradiation by visible light using a $100 \mathrm{~W}$ domestic light bulb. ${ }^{f}$ Kept in the refrigerator overnight.

erature in the presence of the cleavable photoinitiator 2,2dimethoxy-2-phenylacetophenone (DPAP) (Table 1, entries 1 and 2). According to our expectation, $\$$ thiol 2 added exclusively across the exocyclic double bond of the furanose residue providing the 5 '-S-propyl derivative 3. However, a low level of diastereoselectivity (2:1 D-ribo: L-lyxo ratio) was observed and the yield was only $69 \%$ even with 6 equiv. of thiol due to incomplete conversion of $\mathbf{1}$. This result was surprising because Dondoni and Marra described excellent yield and exclusive ribo-selectivity for hydrothiolation of the methyl $\beta$-D-riboside counterpart of $\mathbf{1}$ with a slight excess of thiols. ${ }^{9 a}$ To evaluate if the yield and the stereoselectivity can be influenced by the initiation methods, the reaction was repeated under various conditions including thermal initiation with AIBN, photoredox activation in the presence of $\mathrm{TiO}_{2}{ }^{11}$ or using $\mathrm{Et}_{3} \mathrm{~B}^{12}$ as the radical initiator (Table 1, entries 3-6).

Unfortunately, neither the yield nor the selectivity could be increased. The $\mathrm{Et}_{3} \mathrm{~B}$-catechol reagent system, which was developed for the hydrothiolation of allylic double bonds, ${ }^{12 a}$ showed similar efficacy to the UV-initiated reaction (entries 5 and 1). The other initiation methods proved to be less efficient, due to the low conversion of $\mathbf{1}$ (entries 4 and 6) and the thermal activation even slightly eroded the D-ribo diastereoselectivity (entry 3). Next, the temperature effect on the photoinduced addition was studied. To our great delight, both the stereoselectivity and the yield could substantially be improved by cooling even with a much lower thiol excess (entries 7-9). At

\$ As terminal double bonds react much faster than the internal ones and conjugated double bonds are nonreactive under thio-click conditions (see ref. $6 a$ and $c$ ) chemoselective addition to the exocyclic double bond was expected.
$-30{ }^{\circ} \mathrm{C}$, an $88 \%$ overall yield was achieved with 2 equiv. of thiol, and the stereoselectivity was increased to a $4: 1$ D-ribo: L-lyxo ratio. By cooling the reaction mixture to $-80{ }^{\circ} \mathrm{C}$ the selectivity reached the 5:1 D-ribo: L-lyxo ratio in toluene and the use of a toluene-MeOH 1:1 solvent mixture led to an even higher D-ribo selectivity. Although the cooling was also beneficial for the $\mathrm{Et}_{3} \mathrm{~B}$-catechol-mediated addition (entry 10), the reaction was very sluggish at $-80{ }^{\circ} \mathrm{C}$, and the overall efficacy was inferior to that of the photoinitiated reaction.

After optimizing the conditions of the thiol-ene addition, the substrate scope was investigated. First, compound 1 was reacted with a variety of thiols, including 1-thiosugars 4 and 5 , amino acid derivatives $\mathbf{6 , 7}$ and 9, sulfonic acid salt 8 and dithiol 10, at $-80{ }^{\circ} \mathrm{C}$ with a 1.2:1 thiol: ene ratio (Table 2, entries 1-12).

We were pleased to find that the addition of thiols to the exomethylene moiety of $\mathbf{1}$ occurred with good to excellent yields (71-92\%) and, except for the 1-thiosugar cases, with high levels of D-ribo diastereoselectivity. The reaction was compatible with the carboxylic acid function (entries 7, 8 and 10) and with the sensitive Fmoc group (entry 8) and in most cases reached completion with the slight excess thiol applied. In this context, this method is a mild and economic alternative to the conventional nucleophilic substitution which generally requires strong basic conditions and a higher excess thiol.

$\S$ We have studied the synthesis of $\mathbf{1 7}$ and $\mathbf{1 8}$ by nucleophilic substitution starting from the corresponding 5 '-deoxy-5'-iodo uridine derivative. Compound 17 could be prepared in $76 \%$ yield with 4 equiv. of 6 in the presence of $\mathrm{Cs}_{2} \mathrm{CO}_{3}$. However, analogous reactions of 7 using various bases gave 18 in a yield of up to $20 \%$. 
Table 2 Photoinduced addition of various thiols to 4'-enofuranoside uridine and ribothymidine at low temperature

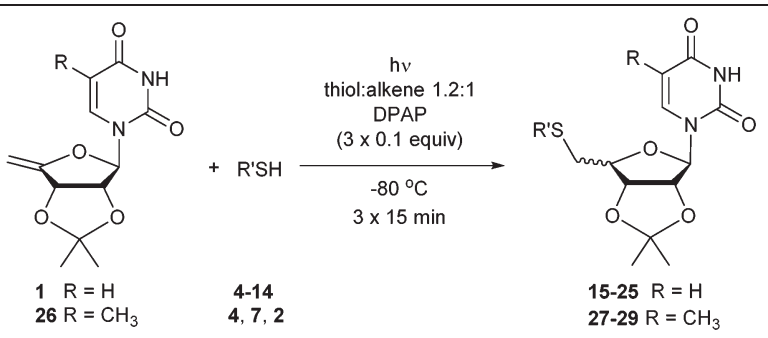

$27-29 \mathrm{R}=\mathrm{CH}_{3}$

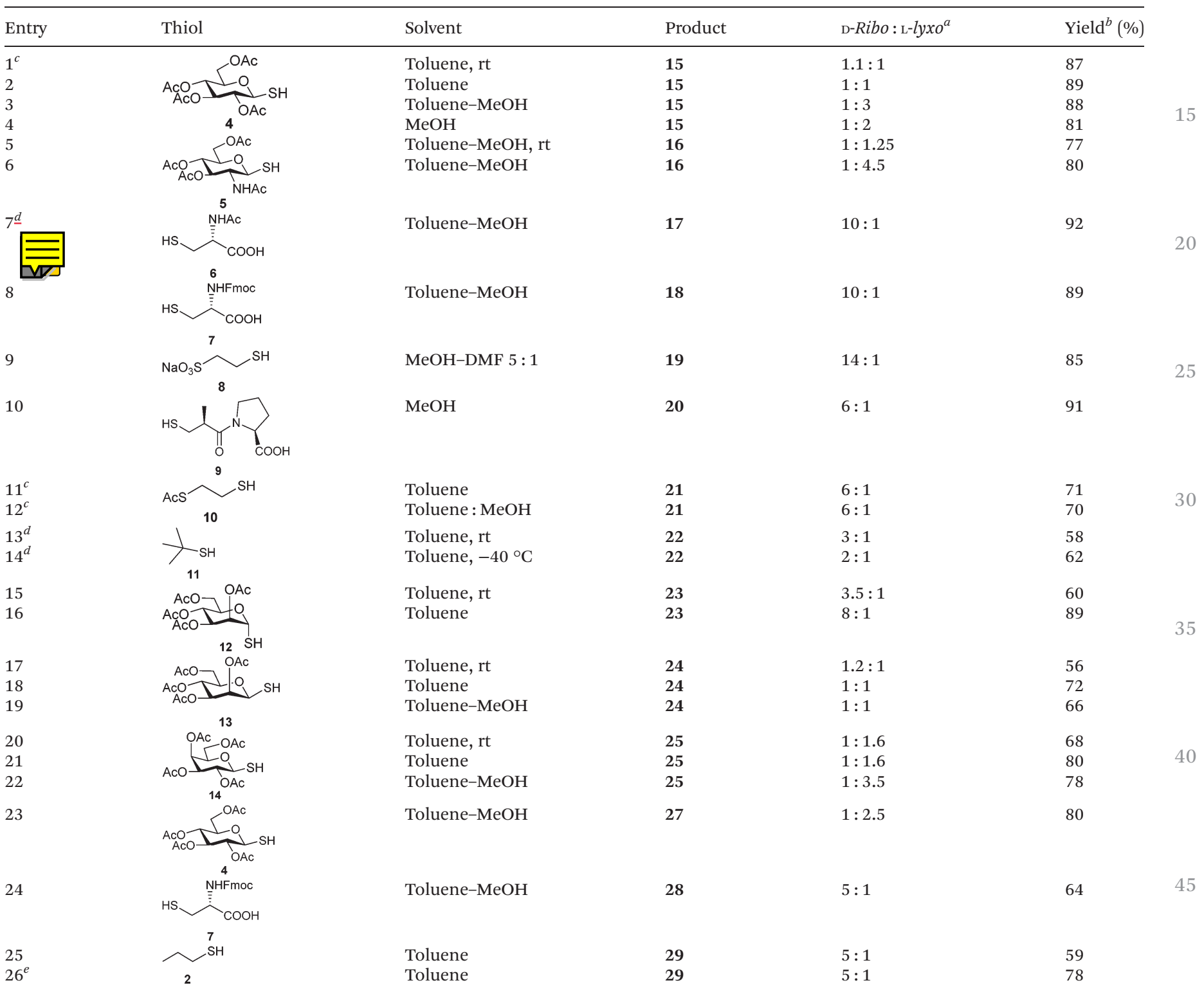
equiv. of thiol was used. ${ }^{e} 3$ equiv. of thiol was used.

Surprisingly, the addition of 1 -thio- $\beta$-D-glucose 4 in toluene, either at room temperature or at $-80{ }^{\circ} \mathrm{C}$, proceeded with a complete lack of stereoselectivity, while running this reaction in $\mathrm{MeOH}$ or in a $\mathrm{MeOH}$-toluene mixture at $-80{ }^{\circ} \mathrm{C}$, a modest L-lyxo selectivity was observed (entries 1-4). Addition of the 2-acetamido-1-thio- $\beta$-D-glucopyranose derivative 5 onto 1 also showed an L-lyxo selectivity which reached the $4.5: 1$ $\mathrm{L}-$ ly $x o$ : D-ribo ratio at $-80{ }^{\circ} \mathrm{C}$ (entries 5 and 6). We assumed that this opposite stereoselectivity was caused by the higher steric demand of the glycosyl thiols relative to the primary 
thiols 6-10. To examine this assumption, the bulky 2-methylpropane-2-thiol 11 was reacted with 1. 1 Unexpectedly, a relatively high D-ribo selectivity (3:1 D-ribo: L-lyxo ratio) was observed at room temperature, which, however, decreased by cooling to a 2:1 D-ribo: L-lyxo ratio (entries 13 and 14). Although this result confirmed that the direction of the $\mathrm{H}$-abstraction by the $C-4^{\prime}$ centered radical intermediate can be influenced not only by the temperature but also the bulkiness of the thiol, it did not explain the lyxo-selectivity observed with the thiosugars 4 and 5. Next, alkene 1 was reacted with the 1-thio- $\alpha$-D-mannopyranose derivative 12 and the $\beta$-thiosugars 13 and 14 (entries 15-22). To our great surprise, the addition of the $\alpha$-thiosugar 12 occurred with a significant D-ribo selectivity at rt which was further increased to a 8:1 D-ribo: L-lyxo ratio when the reaction was carried out at $-80{ }^{\circ} \mathrm{C}$. However, similar reactions with the $\beta$-congener 13 either at $\mathrm{rt}$ or $-80^{\circ} \mathrm{C}$ proceeded with a complete lack of stereoselectivity, while the addition of the 1-thio- $\beta$-D-galactopyranose 14 followed the stereoselectivity of the gluco-epimers 4 and 5. These results clearly demonstrate that the anomeric configuration of the thiosugars exerts a profound effect on the stereochemical outcome of the addition which can also be modified slightly by the solvent and by the $C 2$ configuration. To the best of our knowledge, it has not been observed before that the configuration of the thiols can affect the stereochemical outcome of the thiol-ene coupling.

The thiol-ene reactions of ribothymidine 26 (Table 2, entries 23-26) showed the same stereoselectivity trends as observed with the uridine analogue 1. The addition of 1-thioglucose 4 showed a slight L-lyxo selectivity, while a significant D-ribo preference was observed with the primary thiols 2 and 7 . Although the yields were slightly lower with ribothymidine than uridine, they still remained in a preparatively useful range.

To determine if the protecting groups on the alkene were able to influence the stereochemical outcome of the addition, the uridine derivatives $\mathbf{3 0}$ and $\mathbf{3 2}$ were reacted with thiol $\mathbf{4}$, initially at room temperature. Similar to the analogous reaction of 1, a lack of stereoselectivity was observed with the acetyl-protected alkene 30, moreover, the yields were low (Table 3, entries 1 and 2). Interestingly, the reaction of the tertbutyldimethylsilyl-protected 32 with 4 showed a remarkable $\sim 4$ : 1 L-lyxo selectivity at rt, applying either the UV-irradiation or the $\mathrm{Et}_{3} \mathrm{~B}$-catechol-mediated conditions (Table 3, entries 4 and 5). Repeating the photoinitiated reaction at $-80{ }^{\circ} \mathrm{C}$, an increased 6:1 L-lyxo:D-ribo dr was achieved in an excellent $98 \%$ overall yield (entry 6). The addition of 1-propanethiol onto 32 proceeded with a 2.5:1 L-lyxo preference at room temperature. However, the cooling again favoured the formation of the D-ribo isomer, as observed in the reactions of $\mathbf{1}$

9Due to the low reactivity of the $t$-butylthiyl radical formed (see ref. $8 c$ ), a higher excess of 2-methylpropane-2-thiol was required for the efficient thiol-ene reaction.
Table 3 Hydrothiolation of 4'-methyleneuridine derivatives bearing 1 different protecting groups

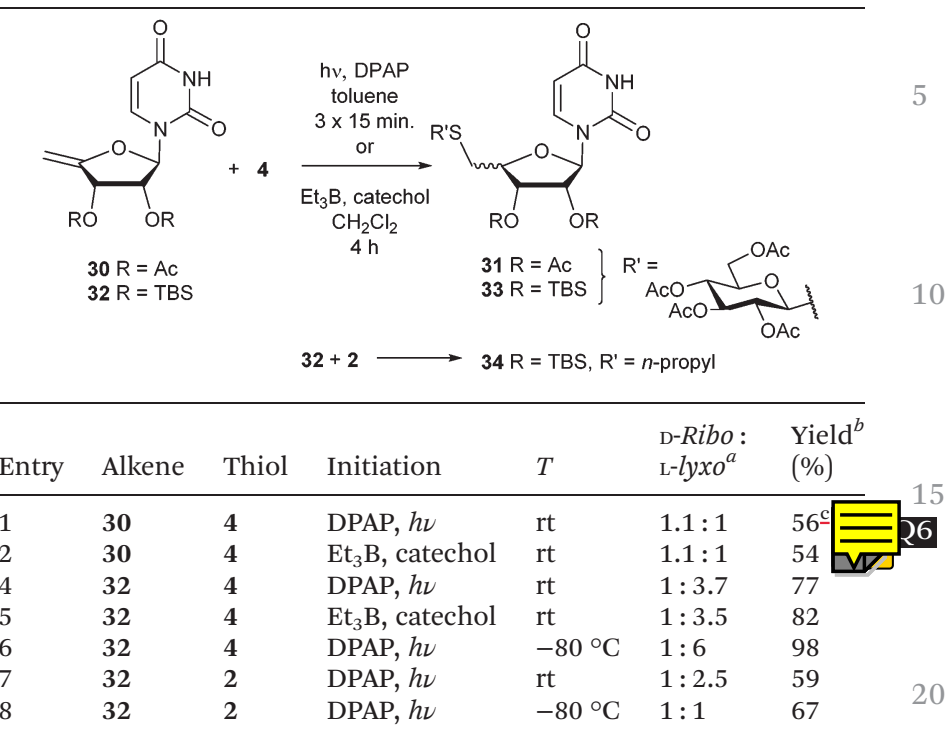

${ }^{a}$ Ratio of products determined by ${ }^{1} \mathrm{H}$ NMR. ${ }^{b}$ Overall yield of products isolated by column chromatography.

with primary thiols and led to the complete loss of stereoselectivity at $-80^{\circ} \mathrm{C}$ (Table 3 , entries 7 and 8).

To further study the alkene scope, compounds 35, 38 and 41 were subjected to thiol-ene reactions. First, 35 bearing the exocyclic double bond at position $C 2^{\prime}$ was hydrothiolated with 2 and 4 (Table 4 ). In contrast to the $C 4^{\prime}$ exomethylene case, the addition reactions across the $C 2^{\prime}$-positioned double bond showed the same trend of D-arabino selectivity using either the primary thiol 2 or the sugar thiol 4. Although a fairly good

Table 4 Hydrothiolation of 2'deoxy-2'-methyleneuridine

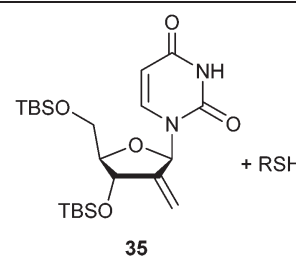

35
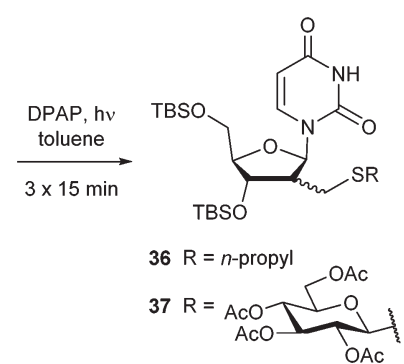

\begin{tabular}{llllll}
\hline Entry & Thiol & Product & $T$ & D-Arabino: D-ribo $^{a}$ & Yield $^{b}(\%)$ \\
\hline 1 & 2 & 36 & rt & $4: 1$ & 39 \\
2 & 2 & 36 & $-80^{\circ} \mathrm{C}$ & $12.5: 1$ & 68 \\
3 & $\mathbf{4}$ & 37 & rt & $5: 1$ & $68^{c}$ \\
4 & $\mathbf{4}$ & 37 & $-80^{\circ} \mathrm{C}$ & $10: 1$ & 89
\end{tabular}

${ }^{a}$ Ratio of products determined by ${ }^{1} \mathrm{H}$ NMR. ${ }^{b}$ Overall yield of products isolated by column chromatography. ${ }^{c}$ Similar results were obtained with $\mathrm{Et}_{3} \mathrm{~B}-$ catechol. 
1 level of diastereoselectivity was observed in favour of the D-arabino isomer at room temperature with both thiols, the yields were only moderate (Table 4 , entries 1 and 3 ). We were pleased to find that running the reactions at $-80{ }^{\circ} \mathrm{C}$ significantly improved the yields and also the levels of diastereoselectivity (Table 4, entries 2 and 4).

Finally, the $C 3^{\prime}$-exomethylene derivatives 38 and 41 were reacted with thiols 2, 4 and 12 (Table 5).

Surprisingly, propanethiol 2 did not react with either of the alkenes at room temperature. However, to our great delight, performing the reactions at $-80{ }^{\circ} \mathrm{C}$ led to the formation of the addition products 39 and 42 with fair yields and excellent D-xylo selectivities (entries 1 and 4). Addition of the $\beta$-1-thioglucose 4 across the $C 3$ '-exomethylene moiety also proceeded with a D-xylo selectivity in all cases (entries 2, 3, 5 and 6). The low level of diastereoselectivity observed at rt was increased to a $90-96 \%$ range by cooling, however, the yields remained moderate (entries 2 vs. 3 and 5 vs. 6). Finally, the $\alpha$-thiosugar 12 was reacted with $\mathbf{4 1}$ in order to study if the anomeric configuration exerts an effect on the stereochemical outcome of the reaction (entry 7 ). In this case, the anomeric configuration did not make any difference in the diastereoselectivity, and the addition of both the $\alpha$-thiosugar 12 and the $\beta$-thiosugar 4 onto 41 occurred at an excellent level of $\mathrm{D}-x y$ lo selectivity providing the corresponding products $\mathbf{4 3}$ and $\mathbf{4 4}$ in the same 50:1 D-xylo: D-ribo ratio (entries 6 and 7).

The source of the stereoselectivity in the thiol-ene coupling of exocyclic alkenes is the preferred $\mathrm{H}$-abstraction by the carbon-centered radical from the thiol into an axial posi-

Table 5 Photoinitiated hydrothiolation of $C 3^{\prime}$-methylene derivatives of uridine (38) and ribothymidine (41)
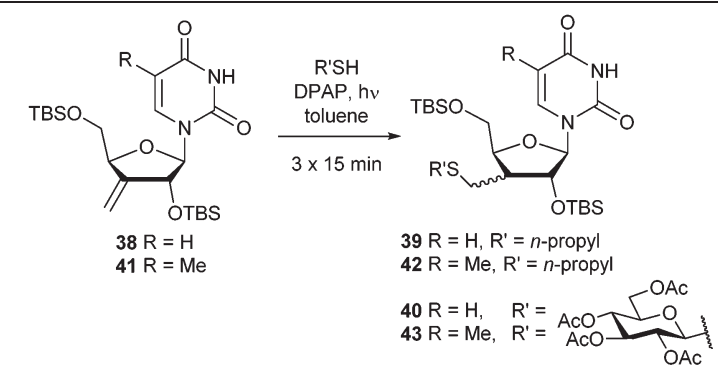

\begin{tabular}{lllllll}
\hline Entry & Alkene & Thiol & Product & $T$ & DXylo: $:$-ribo $^{a}$ & Yield $^{b}$ \\
\hline $1^{c}$ & $\mathbf{3 8}$ & $\mathbf{2}$ & $\mathbf{3 9}$ & $-80^{\circ} \mathrm{C}$ & $50: 1$ & $75 \%$ \\
$2^{d}$ & $\mathbf{3 8}$ & $\mathbf{4}$ & $\mathbf{4 0}$ & $\mathrm{rt}$ & $3: 1$ & $26 \%$ \\
$3^{d}$ & $\mathbf{3 8}$ & $\mathbf{4}$ & $\mathbf{4 0}$ & $-80^{\circ} \mathrm{C}$ & $17: 1$ & $49 \%$ \\
$4^{c, d}$ & $\mathbf{4 1}$ & $\mathbf{2}$ & $\mathbf{4 2}$ & $-80^{\circ} \mathrm{C}$ & $12.5: 1$ & $39 \%$ \\
$5^{d}$ & $\mathbf{4 1}$ & $\mathbf{4}$ & $\mathbf{4 3}$ & $\mathrm{rt}$ & $2: 1$ & $27 \%$ \\
$6^{d}$ & $\mathbf{4 1}$ & $\mathbf{4}$ & $\mathbf{4 3}$ & $-80^{\circ} \mathrm{C}$ & $50: 1$ & $30 \%$ \\
7 & $\mathbf{4 1}$ & $\mathbf{1 2}$ & $\mathbf{4 4}$ & $-80^{\circ} \mathrm{C}$ & $50: 1$ & $60 \%$
\end{tabular}

${ }^{a}$ Ratio of products determined by ${ }^{1} \mathrm{H}$ NMR. ${ }^{b}$ Overall yield of products isolated by column chromatography. ${ }^{c}$ No reaction observed at room temperature. ${ }^{d}$ Unreacted starting compounds were recovered.
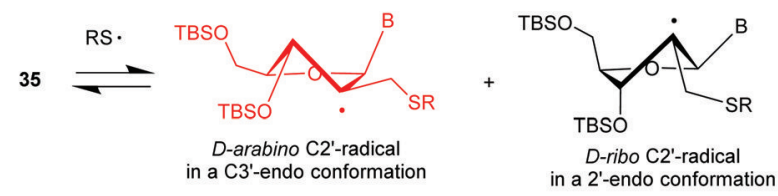

1
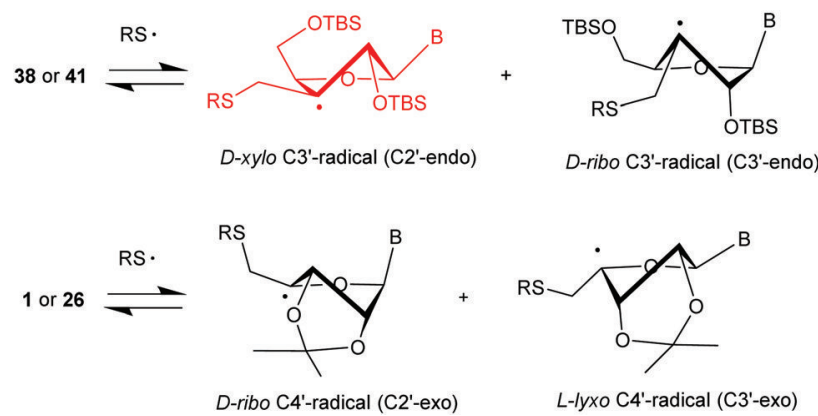

L-lyxo C4'-radical (C3'-exo)

Scheme 1 Equatorial C2', C3' and C4' radical intermediates formed in the first, reversible step of the thiol-ene reactions. All-equatorial radicals are highlighted in red.

tion. ${ }^{6 d, 13}$ We assume that the reactions presented herein proceed through the equatorial radicals depicted in Scheme 1, and the stereochemical outcome of the reactions is controlled by the relative stability of the radical pairs. Our results suggest that the proportion of the more stable radical intermediate and thus the level of stereoselectivity in a given reaction can be greatly increased by cooling the reaction to $-80{ }^{\circ} \mathrm{C}$.

In the case of the $C 2^{\prime}$ - and $C 3^{\prime}$-exomethylene derivatives, the reactions preferably go through the more stable radicals possessing an all-equatorial substitution pattern, leading to the observed D-arabino-selectivity from the $C 2^{\prime}$-alkene 35 and the D-xylo-selectivity from the $C 3^{\prime}$-alkenes 38 and 41 (Scheme 1). Although the participation of the less stable D-ribo-configured $C 2$ '- and $C 3^{\prime}$-radicals is not negligible in the room-temperature reactions, which explains the low/moderate levels of diastereoselectivity at rt, it can be significantly suppressed by cooling resulting in the observed excellent diastereoselectivities.

For the 4'-exomethylene derivatives 1, 26, 30 and 32, the stereochemical outcome of the reactions can be influenced by many factors including the solvent, the protecting groups and the size and configuration of the thiols. Our results demonstrate that the low-temperature reactions of $\mathbf{1}$ and 26 with primary thiols, as well as with the 1-thiomannose derivative 12, preferentially go through the D-ribo $C 4^{\prime}$-radical, existing in the $C 2$ '-exo $\left({ }^{3} \mathrm{~T}_{2}\right)$ conformation, leading to the good D-riboselectivities. We assume that the anomalous stereochemical results observed with the bulky thiol 11 and the $\beta$-D-gluco-configured 1-thiosugars $(4,5,13$ and 14) can be explained by the steric congestion of the carbon-centered radicals and, possibly, by a steric mismatch between the thiosugars and the D-ribo configured $C 4^{\prime}$-radicals formed from 1, 26 or $32 .{ }^{14}$ Due to this steric mismatch, the L-lyxo radicals participate in the $\mathrm{H}$-abstraction step in an increased extent compared to the reactions of primary thiols, thus leading to the increased ratio of the L-lyxo isomer in the products. 


\section{Conclusion}

In conclusion, we have demonstrated that the low-temperature photoinitiated thiol-ene reaction provides a facile approach to various sugar-modified nucleosides including 5 '-thiosubstituted D-ribo or L-lyxo derivatives, as well as valuable $C 2^{\prime}$ - and $C 3$ '-branched compounds with D-arabino- or D-xylo configuration.

The low or moderate stereoselectivity observed at rt upon hydrothiolation of the $C 2$ '- and $C 3^{\prime}$-exomethylene nucleosides 35, 36 and 41 could be greatly increased by cooling, and the corresponding $C 2^{\prime}$-branched D-arabinosyl and the $C 3^{\prime}$-branched D-xylosyl derivatives could be produced with good to excellent selectivity.

Our study revealed that the stereoselectivity of the thiol-ene coupling of the $4^{\prime}, 5^{\prime}$-unsaturated nucleosides is not easy to predict, probably due to the comparable stability of the corresponding D-ribo and L-lyxo radical intermediates. Nevertheless, good levels of D-ribo selectivity could be achieved in the lowtemperature reactions of the isopropylidene-protected uridine 1 with primary thiols. Interestingly, the $\beta$-configured thiosugars did not follow this trend, instead, they tend to react with an L-lyxo selectivity at low temperature.

Besides enhancing the stereoselectivity, the low temperature also enhances the yield of the thiol-ene coupling, assumedly, by exerting a beneficial effect on the overall kinetics of the reaction.

The investigation of the scope and potential of the lowtemperature thiol-ene coupling on purine nucleosides and on sugar-alkenes with an endocyclic double bond is underway.

\section{Experimental}

\section{General information}

2,3,4,6-Tetra- $O$-acetyl-1-thio- $\beta$-D-glucopyranose $(4),{ }^{16} 2$-acetamido-3,4,6-tri-O-acetyl-2-deoxy-1-thio- $\beta$-D-glucopyranose (5), ${ }^{17}$
$N$-(9-fluorenylmethoxycarbonyl)-L-cysteine (7), ${ }^{18} S$-(2-mercaptoethyl)thioacetate $(\mathbf{1 0}),{ }^{19} 2,3,4,6$-tetra- $O$-acetyl-1-thio- $\alpha$-D-mannopyranose $(\mathbf{1 2}),^{20} \quad 2,3,4,6$-tetra- $O$-acetyl-1-thio- $\beta$-D-mannopyranose $(\mathbf{1 3}),{ }^{20}$ and $2,3,4,6$-tetra- $O$-acetyl-1-thio- $\beta$-D-galactopyranose $(\mathbf{1 4})^{21}$ were prepared according to the literature procedures. 2,2-Dimethoxy-2-phenylacetophenone (DPAP) and thiols 2, 6-9 and 11 were purchased from Sigma Aldrich Chemical Co. and used without further purification. The synthesis of nucleoside enofuranosides 1, 26, 30, 32, 35, 38 and 41 is described in the ESI. $\dagger$ Optical rotations were measured at room temperature with a PerkinElmer 241 automatic polarimeter. TLC was performed on a Kieselgel $60 \mathrm{~F}_{254}$ (Merck) with detection by UV-light (254 $\mathrm{nm})$ and immersing into sulfuric acid ammonium-molybdate solution or $5 \%$ ethanolic sulfuric acid followed by heating. Flash column chromatography was performed on Silica gel 60 (Merck 0.040-0.063 mm). Organic solutions were dried over anhydrous $\mathrm{Na}_{2} \mathrm{SO}_{4}$ or $\mathrm{MgSO}_{4}$, and concentrated under vacuum. The ${ }^{1} \mathrm{H}$ NMR (360 and $400 \mathrm{MHz}$ ) and ${ }^{13} \mathrm{C}$ NMR (90 and $100 \mathrm{MHz}$ ) spectra were recorded on Bruker DRX-360 and Bruker DRX-400 spectrometers at $25{ }^{\circ} \mathrm{C}$. Chemical shifts are referenced to $\mathrm{Me}_{4} \mathrm{Si}\left(0.00 \mathrm{ppm}\right.$ for $\left.{ }^{1} \mathrm{H}\right)$ and to the residual solvent signals $\left(\mathrm{CDCl}_{3}: 77.2, \mathrm{DMSO}_{6}: 39.5\right.$, $\mathrm{CD}_{3} \mathrm{OD}: 49.0$ for ${ }^{13} \mathrm{C}$ ). Two-dimensional COSY and ${ }^{1} \mathrm{H}_{-}{ }^{13} \mathrm{C}$ HSQC experiments were used to assist NMR assignments and 2D ROESY spectra were used for configurational assignments. MALDI-TOF MS analyses of the compounds were carried out in the positive reflectron mode using a BIFLEX III mass spectrometer (Bruker, Germany) equipped with delayed-ion extraction. 2,5-Dihydroxybenzoic acid (DHB) was used as a matrix and $\mathrm{F}_{3} \mathrm{CCOONa}$ as a cationising agent in DMF. ESI-TOF MS spectra were recorded by using a microTOF-Q type QqTOFMS mass spectrometer (Bruker) in the positive ion mode using $\mathrm{MeOH}$ as the solvent. Elemental analysis (C, H, N and S) was performed on an Elementar Vario MicroCube instrument.

The photoinitiated reactions were carried out in a borosilicate vessel by irradiation with a Hg-lamp giving maximum emission at $365 \mathrm{~nm}$, without any caution to exclude air or moisture.

\section{Representative example for the photoinduced addition of thiols to alkenes at $-80^{\circ} \mathrm{C}$ in the presence of DPAP}

$2^{\prime}, 3^{\prime}$-O-Isopropylidene- $5^{\prime}-S$ - $n$-propyl-5'-thiouridine (3a) and 1-(2',3'-O-isopropylidene-5'-S-n-propyl-5'-thio- $\alpha$-L-lyxofuranosyl) uracil (3b). To a solution of alkene 1 (90 $\mathrm{mg}, 0.3 \mathrm{mmol}$ ) and thiol 2 (0.6 mmol, 2 equiv., $60 \mu \mathrm{L})$ in toluene $(1 \mathrm{~mL}) 2$,2dimethoxy-2-phenylacetophenone $(7.7 \mathrm{mg}, 0.03 \mathrm{mmol})$ was added. The reaction mixture was cooled to $-80{ }^{\circ} \mathrm{C}$ and irradiated with UV light for $15 \mathrm{~min}$. After $15 \mathrm{~min}$ DPAP $(7.7 \mathrm{mg}$, $0.03 \mathrm{mmol})$ dissolved in toluene $(0.3 \mathrm{~mL})$ was added, and the mixture was cooled to $-80{ }^{\circ} \mathrm{C}$ and irradiated for another 15 min. The addition of DPAP and irradiation at this temperature was repeated once more. Then the solution was concentrated and the crude product was purified by flash column chromatography (gradient elution 8:2 $\rightarrow$ 7:3 n-hexaneacetone) to give a $5: 1$ mixture of $\mathbf{3 a}$ and $\mathbf{3 b}(103 \mathrm{mg}, 89 \%)$. A second flash column chromatography (95: $5 \mathrm{CH}_{2} \mathrm{Cl}_{2}$-acetone) 
of the diastereomeric mixture gave pure $3 \mathrm{a}\left(R_{\mathrm{f}}=0.31,7: 3\right.$ $n$-hexane-acetone) as a colourless syrup and pure $3 \mathbf{b}\left(R_{\mathrm{f}}=0.30\right.$, $7: 3 n$-hexane-acetone) as a colourless syrup.

Compound $3 \boldsymbol{a}$ (D-ribo product). ${ }^{1} \mathrm{H}$ NMR $\left(400 \mathrm{MHz}, \mathrm{CDCl}_{3}\right.$ ) $\delta(\mathrm{ppm}) 9.89(\mathrm{~s}, 1 \mathrm{H}, \mathrm{N} H), 7.37$ (d, $J=8.1 \mathrm{~Hz}, 1 \mathrm{H}, \mathrm{H}-6$ uracil), $5.75\left(\mathrm{~d}, J=8.1 \mathrm{~Hz}, 1 \mathrm{H}, \mathrm{H}-5\right.$ uracil), $5.69\left(\mathrm{~d}, J_{1^{\prime}, 2^{\prime}}=2.2 \mathrm{~Hz}, 1 \mathrm{H}\right.$, $\mathrm{H}-1^{\prime}$ ), 4.99 (dd, $\left.J_{2^{\prime}, 3^{\prime}}=6.6 \mathrm{~Hz}, J_{1^{\prime}, 2^{\prime}}=2.2 \mathrm{~Hz}, 1 \mathrm{H}, \mathrm{H}-2^{\prime}\right), 4.82$ (dd, $\left.J_{2^{\prime}, 3^{\prime}}=6.6 \mathrm{~Hz}, J_{3^{\prime}, 4^{\prime}}=4.2 \mathrm{~Hz}, 1 \mathrm{H}, \mathrm{H}-3^{\prime}\right), 4.27\left(\mathrm{td}, J_{4^{\prime}, 5^{\prime}}=6.1 \mathrm{~Hz}\right.$, $\left.J_{3^{\prime}, 4^{\prime}}=4.3 \mathrm{~Hz}, 1 \mathrm{H}, \mathrm{H}-4^{\prime}\right), 2.92-2.80$ (m, 2H, H-5'a,b), 2.55 (t, $J=$ $\left.7.5 \mathrm{~Hz}, 2 \mathrm{H}, \mathrm{CH}_{3} \mathrm{CH}_{2} \mathrm{CH}_{2}\right), 1.63(\mathrm{dt}, J=14.7 \mathrm{~Hz}, J=7.4 \mathrm{~Hz}, 2 \mathrm{H}$, $\mathrm{CH}_{3} \mathrm{CH}_{2} \mathrm{CH}_{2}$ ), 1.57 (s, 3H, i-propylidene $\mathrm{CH}_{3}$ ), 1.36 (s, 3H, i-propylidene $\left.\mathrm{CH}_{3}\right), 0.98\left(\mathrm{t}, J=7.3 \mathrm{~Hz}, 3 \mathrm{H}, \mathrm{CH}_{3} \mathrm{CH}_{2} \mathrm{CH}_{2}\right) ;{ }^{13} \mathrm{C} \mathrm{NMR}$ $\left(100 \mathrm{MHz}, \mathrm{CDCl}_{3}\right) \delta(\mathrm{ppm}) 163.8,150.1(2 \mathrm{C}, 2 \times \mathrm{CO}$ uracil), C-5 uracil), 94.2 (1C, C-1'), 86.7 (1C, C-4'), 84.5 (1C, C-2'), 83.2 (1C, $\left.\mathrm{C}-3^{\prime}\right), 35.1\left(1 \mathrm{C}, \mathrm{CH}_{3} \mathrm{CH}_{2} \mathrm{CH}_{2}\right.$ ), 34.5 (1C, C-5'), 27.2, 25.4 (2C, $2 \times$ i-propylidene $\mathrm{CH}_{3}$ ), $23.0\left(1 \mathrm{C}, \mathrm{CH}_{3} \mathrm{CH}_{2} \mathrm{CH}_{2}\right), 13.5(1 \mathrm{C}$, $\mathrm{CH}_{3} \mathrm{CH}_{2} \mathrm{CH}_{2}$ ); MALDI-TOF MS: $\mathrm{m} / z$ calcd for $\mathrm{C}_{15} \mathrm{H}_{22} \mathrm{~N}_{2} \mathrm{NaO}_{5} \mathrm{~S}$ $[\mathrm{M}+\mathrm{Na}]^{+}$365.114, found 365.119.

Compound $3 \boldsymbol{b}$ (L-lyxo product). ${ }^{1} \mathrm{H}$ NMR $\left(400 \mathrm{MHz}, \mathrm{CDCl}_{3}\right)$ $\delta(\mathrm{ppm}) 9.31(\mathrm{~s}, 1 \mathrm{H}, \mathrm{NH}), 7.22(\mathrm{~d}, J=8.0 \mathrm{~Hz}, 1 \mathrm{H}, \mathrm{H}-6$ uracil), 5.73 (dd, $J=8.1 \mathrm{~Hz}, J=1.8 \mathrm{~Hz}, 1 \mathrm{H}, \mathrm{H}-5$ uracil), $5.36(\mathrm{~s}, 1 \mathrm{H}$, $\left.J_{3^{\prime}, 4^{\prime}}=3.9 \mathrm{~Hz}, 1 \mathrm{H}, \mathrm{H}-3^{\prime}\right), 4.59\left(\mathrm{td}, J_{4^{\prime}, 5^{\prime}}=6.8 \mathrm{~Hz}, J_{3^{\prime}, 4^{\prime}}=3.9 \mathrm{~Hz}\right.$, $\left.0.8 \mathrm{~Hz}, 2 \mathrm{H}, \mathrm{CH}_{3} \mathrm{CH}_{2} \mathrm{CH}_{2}\right), 1.65-1.57\left(\mathrm{~m}, 2 \mathrm{H}, \mathrm{CH}_{3} \mathrm{CH}_{2} \mathrm{CH}_{2}\right), 1.52$ (s, 3H, i-propylidene $\mathrm{CH}_{3}$ ), 1.36 (s, 3H, i-propylidene $\mathrm{CH}_{3}$ ), 0.99 (t, $\left.J=7.3 \mathrm{~Hz}, 3 \mathrm{H}, \mathrm{CH}_{3} \mathrm{CH}_{2} \mathrm{CH}_{2}\right) ;{ }^{13} \mathrm{C}$ NMR $\left(100 \mathrm{MHz}, \mathrm{CDCl}_{3}\right)$ 113.3 (1C, i-propylidene $C_{\mathrm{q}}$ ), 102.5 (1C, C-5 uracil), 97.4 (1C, C-1'), 85.8 (1C, C-4'), 85.5 (1C, C-2'), 81.6 (1C, C-3'), 35.1 (1C, $\mathrm{CH}_{3} \mathrm{CH}_{2} \mathrm{CH}_{2}$ ), 31.1 (1C, C-5'), 26.4, 24.9 (2C, $2 \times$ i-propylidene $\left.\mathrm{CH}_{3}\right), 23.1$ (1C, $\mathrm{CH}_{3} \mathrm{CH}_{2} \mathrm{CH}_{2}$ ), 13.6 (1C, $\mathrm{CH}_{3} \mathrm{CH}_{2} \mathrm{CH}_{2}$ ); ESI-TOF MS: $m / z$ calcd for $\mathrm{C}_{15} \mathrm{H}_{22} \mathrm{~N}_{2} \mathrm{NaO}_{5} \mathrm{~S}[\mathrm{M}+\mathrm{Na}]^{+} 365.114$, found 365.122 .

\section{Conflicts of interest}

There are no conflicts of interest to declare.

\section{Acknowledgements}

The authors gratefully acknowledge financial support for this research from the National Research, Development and Innovation Office of Hungary (OTKA K 109208 and TÉT_15_IN-1-2016-0071). The research was also supported by the EU and co-financed by the European Regional Development Fund under the project GINOP-2.3.2-15-2016-00008.

\section{$55 \quad$ Notes and references}

1 L. P. Jordheim, D. Durantel, F. Zoulim and C. Dumontet, Nat. Rev. Drug Discovery, 2013, 12, 447. 142.5 (1C, C-6 uracil), 114.7 (1C, i-propylidene $C_{\mathrm{q}}$ ), 102.7 (1C, $\left.\mathrm{H}-1^{\prime}\right), 5.24\left(\mathrm{~d}, J_{2^{\prime}, 3^{\prime}}=6.0 \mathrm{~Hz}, 1 \mathrm{H}, \mathrm{H}-2^{\prime}\right), 4.99\left(\mathrm{dd}, J_{2^{\prime}, 3^{\prime}}=5.9 \mathrm{~Hz}\right.$, $\left.1 \mathrm{H}, \mathrm{H}-4^{\prime}\right), 2.88-2.76\left(\mathrm{~m}, 2 \mathrm{H}, \mathrm{H}-5^{\prime} \mathrm{a}, \mathrm{b}\right), 2.57$ (td, $J=7.2 \mathrm{~Hz}, J=$ $\delta(\mathrm{ppm}) 163.7,150.8$ (2C, $2 \times C \mathrm{C}$ uracil), 143.7 (1C, C-6 uracil),
2 (a) E. Ichikawa and K. Kato, Curr. Med. Chem., 2001, 8, 385; (b) S. Singh, D. Bhattarai, G. Veeraswamy, Y. Choi and K. Lee, Curr. Org. Chem., 2016, 20, 856.

3 (a) M. Thomsen, S. B. Vogensen, J. Buchardt, M. D. Burkart and R. P. Clausen, Org. Biomol. Chem., 2013, 11, 7606; D. Datta, A. Samanta, S. Dasgupta and T. Pathak, RSC Adv., 2014, 4, 2214; (b) K. Kai, H. Fujii, R. Ikenaka, M. Akagawa and H. Hayashi, Chem. Commun., 2014, 50, 8586; (€) B. D. Horning, R. M. Suciu, D. A. Ghadiri, O. A. Ulanovskaya, M. L. Matthews, K. M. Lum, K. M. Backus, S. J. Brown, H. Rosen and B. F. Cravatt, J. Am. Chem. Soc., 2016, 138, 13335.

4 H. Kaur, B. R. Babu and S. Maiti, Chem. Rev., 2007, 107, 4672 .

5 (a) T. Posner, Ber. Dtsch. Chem. Ges., 1905, 38, 646; (b) K. Griesbaum, Angew. Chem., Int. Ed. Engl., 1970, 9, 273.

6 (a) C. E. Hoyle, T. Y. Lee and T. J. Roper, J. Polym. Sci., Part A: Polym. Chem., 2004, 42, 5301; (b) A. Dondoni, Angew. Chem., Int. Ed., 2008, 47, 8995; (c) C. E. Hoyle and C. N. Bowman, Angew. Chem., Int. Ed., 2010, 49, 1540; (d) F. Dénès, M. Pichowicz, G. Povie and P. Renaud, Chem. Rev., 2014, 114, 2587.

7 (a) A. Dondoni and A. Marra, Chem. Soc. Rev., 2012, 41, 573; (b) L. McSweeney, F. Dénès and E. M. Scanlan, Eur. J. Org. Chem., 2016, 2080.

8 (a) L. Lázár, M. Csávás, M. Herczeg, P. Herczegh and A. Borbás, Org. Lett., 2012, 14, 4650; (b) L. Lázár, M. Csávás, Á. Hadházi, M. Herczeg, M. Tóth, L. Somsák, T. Barna, P. Herczegh and A. Borbás, Org. Biomol. Chem., 2013, 11, 5339; (c) L. Lázár, M. Csávás, M. Tóth, L. Somsák and A. Borbás, Chem. Pap., 2015, 69, 889; (d) J. József, L. Juhász, T. Z. Illyés, M. Csávás, A. Borbás and L. Somsák, Carbohydr. Res., 2015, 413, 63; (e) L. Lázár, L. Juhász, G. Batta, A. Borbás and L. Somsák, New J. Chem., 2017, 41, 1284.

9 (a) M. Fiore, A. Marra and A. Dondoni, J. Org. Chem., 2009, 74, 4422; (b) S. Staderini, A. Chambery, A. Marra and A. Dondoni, Tetrahedron Lett., 2012, 53, 702.

10 (a) A. Malone and E. M. Scanlan, Org. Lett., 2013, 15, 504;

(b) E. M. Scanlan, V. Corcé and A. Malone, Molecules, 2014, 19, 19137.

11 V. T. Bhat, P. A. Duspara, S. Seo, N. S. B. Abu Bakar and M. F. Greaney, Chem. Commun., 2015, 51, 4383.

12 (a) G. Povie, A.-T. Tran, D. Bonnaffé, J. Habegger, Z. Hu, C. Le Narvor and P. Renaud, Angew. Chem., Int. Ed., 2014, 53, 3894; (b) J. Gorges and U. Kazmaier, Eur. J. Org. Chem., 2015, 4422; (c) L. Lázár, M. Nagy, A. Borbás, P. Herczegh, M. Zsuga and S. Kéki, Eur. J. Org. Chem., 2015, 7675.

13 (a) F. G. Bordwell, P. S. Landis and G. S. Whitney, J. Org. Chem., 1965, 30, 3764; (b) A. LeBel, R. F. Czaja and A. DeBoer, J. Org. Chem., 1969, 34, 3112.

14 (a) S. Masamune, W. Choy, J. S. Petersen and L. R. Sita, Angew. Chem., Int. Ed. Engl., 1985, 24, 1; (b) N. M. Spijker and A. A. van Boeckel, Angew. Chem., Int. Ed. Engl., 1991, 30, 180; (c) B. Fraser-Reid, J. C. Lopez, 
K. V. Radhakrishnan, M. Mach, U. Schlueter, A. M. Gomez and C. Uriel, J. Am. Chem. Soc., 2002, 124, 3198.

15 (a) N. B. Cramer, S. K. Reddy, A. K. O'Brien and C. N. Bowman, Macromolecules, 2003, 36, 7964; (b) B. H. Northrop and R. N. Coffey, J. Am. Chem. Soc., 2012, 134, 13804.

16 D. Horton, Methods Carbohydr. Chem., 1963, 2, 433.

17 W. M. zu Reckendorf and W. A. Bonner, J. Org. Chem., 1961, 26, 4596.
18 M. Kicsák, M. Bege, I. Bereczki, M. Csávás, M. Herczeg, Z. Kupihár, L. Kovács, A. Borbás and P. Herczegh, Org. Biomol. Chem., 2016, 14, 3190.

19 J. Xun, H. Huang, K. W. Vogel and D. G. Drueckhammer, Bioorg. Chem., 2005, 33, 90.

20 K. L. Matta, R. N. Girotra and J. J. Barlow, Carbohydr. Res., 1975, 43, 101.

21 M. Cerny, J. Stanek and J. Pacak, Monatsh. Chem., 1963, 94, 290. 